\title{
Variation in leaf anatomical traits of Betula albosinensis at different altitudes reflects the adaptive strategy to environmental changes
}

\author{
Jun Yang, Guopeng Chen, Peifang Chong*, Ketong Yang, Jinwu Zhang, Mei Wang \\ College of Forestry, Gansu Agricultural University, Lanzhou 730070 China \\ *Corresponding author, e-mail: zhongpf@gsau.edu.cn
}

\begin{abstract}
The ability of plants to adapt to environmental variability and self-regulate in complex habitats often reflected in leaf anatomical changes. In an assessment of 19 characteristics of Betula albosinensis leaves, samples were taken from trees grown along an altitudinal gradient on the eastern edge of the Qinghai-Tibet Plateau and distributed at three altitudes: $2434 \mathrm{~m}, 2824 \mathrm{~m}$, and $3060 \mathrm{~m}$. Anatomical characteristics of the leaves' blade, mesophyll, and midrib were studied using paraffin slice technology. We found that altitudes and changes in altitude affected the leaf anatomy. As altitude increased, the blade and the mesophyll became thinner, and the transport tissues of the midrib became relatively underdeveloped. However, intra-altitudinal variation was the main source of phenotypic variance. Pearson correlation and principal component analysis revealed that each trait had different ecological dimensions, and that there were trade-offs and covariance relationships between traits. In summary, to adapt to the local altitudinal conditions, Betula albosinensis may exhibit multiple responses, such as reducing investment in leaves, which can boost short-term growth rates, and the "quick investment and return" strategy. Our findings are useful in understanding anatomical adaptations and their trade-offs to environmental variation.
\end{abstract}

KEYWORDS: ecological adaptation, anatomical traits, phenotypic differentiation, Betula albosinensis

\section{INTRODUCTION}

Epidermis, mesophyll, and veins are the three main sections of leaves. Epidermal cells are largely responsible for insulation, water retention, and resistance to herbivores and diseases [1]. The mesophyll palisade tissue contains most of the photosynthetic chloroplasts, and the spongy tissue influences carbon and water exchange between the leaf and the atmosphere. The morphological characteristics of mesophyll can intuitively represent a plant's photosynthesis and water consumption efficiency [2]. Leaf veins contain vascular bundles composing of xylem and phloem wrapped around with vascular bundle sheath cells and responsible for material transport, mechanical support, and herbivore and disease resistance [3]. The ergastic content of the midrib vascular bundles can change cell osmotic pressure and alleviate stress: plants with welldeveloped vascular systems tend to be more resistant to stress. The midrib characteristics directly affect the growth and development of plants and, thus, their productivity [4]. The epidermis, the mesophyll, and the leaf veins all respond to environmental changes in different ways and with different sensitivities, and leaves adapt to environmental changes by mediating the covariance and trade-offs between different anatomical traits [5-8].

Leaves are typically a plant organ with the most surface area exposed to the environment [9], as well as the most often exchanging materials and energy with it. Leaves are sensitive to ecological factors and have strong plasticity. Under different environmental pressures, the anatomical characteristics of leaves have evolved special characteristics that are compatible with heterogeneous habitats [10]. Drought stress has been shown to thicken the stratum corneum and palisade tissue of Populus euphratica [11], but decrease leaf thickness in Eucalyptus robusta [12]. In Salix matsudana, leaf and upper epidermis thickness decreased as air pollution levels rose, but the opposite trend was observed in Syringa oblata [13]. Anatomical changes within a single species can clarify plant response mechanisms to the environment [14], but there are currently relatively few studies on the changes in leaf anatomical traits along the gradient of natural environment and the response of midrib to the environment.

Elevation is a dominant environmental factor affecting differentiation of mountain vegetation and plant interactions with light, precipitation, temperature, and radiation. As a response to life at high elevations, Polygonum paleaceum [15], Carum carvi [16], and Populus euphratica [17] produced thicker cell walls, upper and lower epidermis, spongy tissue, and palisade tissue. However, some studies have found the opposite trends. For example, at higher elevations, Meconopsis integrifolia exhibited reduced leaf thickness [18]; and the palisade and spongy tissues of Picea likiangensis [19] and Campylotropis polyantha [20] became thinner.

Betula albosinensis is endemic to China, widely distributed in southwest, northwest, and north China from $1800 \mathrm{~m}$ to $3200 \mathrm{~m}$ above sea level. This tree 
species is highly adaptable to its surroundings, with few requirements for soil type, terrain, or topography, allowing it to thrive in a variety of environments. Betula albosinensis is a pioneer tree species in locations with exceptionally bare soil, as well as a critical species for secondary succession following the collapse of subalpine forests. It performs ecological services, such as soil and water conservation, and is a major factor maintaining the regional ecological balance [21]. Through a comparative analysis of Betula albosinensis leaf anatomical traits at three elevations (2434 m, $2824 \mathrm{~m}$, and $3060 \mathrm{~m}$ ), we attempted to discuss the following three questions: (1) Were the Betula albosinensis leaf anatomical traits responded to changes in altitude?; (2) Did changes in altitude affect the anatomical traits of Betula albosinensis leaves?; and (3) Did plants' trade-offs reflect strategies and mechanisms for adjusting to changes of altitude?

\section{MATERIALS AND METHODS}

\section{Study sites}

Our study sites were located in the Bailongjiang National Forest Ecosystem Research Station in Gansu Province, China $\left(104^{\circ} 02^{\prime} 15^{\prime \prime}-104^{\circ} 22^{\prime} 05^{\prime \prime} \mathrm{E}\right.$, $33^{\circ} 34^{\prime} 10^{\prime \prime}-33^{\circ} 46^{\prime} 25^{\prime \prime} \mathrm{N}, 1790-4536 \mathrm{~m}$ ) on the eastern edge of the Qinghai-Tibet Plateau. This region is situated at the confluence of the temperate monsoon, subtropical monsoon, and plateau mountainous climate zone and the boundary between China's semihumid and semi-arid regions. The average annual temperature is $4.3^{\circ} \mathrm{C}$, and the average temperatures in the hottest month (July) and the coldest month (January) are $20.8{ }^{\circ} \mathrm{C}$ and $-13.3^{\circ} \mathrm{C}$, respectively. The annual average frost-free period is about 96.7 days. The annual average precipitation is $951.0 \mathrm{~mm}$, which is concentrated from July to September when $70 \%$ $(918.8 \mathrm{~mm})$ falls as rain, and the air relative humidity is $82 \%$. The average sunshine duration is $1398.4 \mathrm{~h}$ per year, and the daily illumination rate is $32 \%$ [21].

\section{Field sampling}

According to a comprehensive survey conducted in the research region in August 2019, the distribution and growth of Betula albosinensis were discovered at three altitudes: $2434 \mathrm{~m}, 2824 \mathrm{~m}$, and $3060 \mathrm{~m}$; therefore, the transects were set at these three elevations. At each elevation, 10 healthy Betula albosinensis individual trees at a distance of at least $10 \mathrm{~m}$ apart were randomly selected, and the well-growing branchlets of the current year from the east, south, west, and north were cut with pruning clippers. Then 3 fully expanded mature leaves between the fifth leaf from the tip of the branchlets and the base were selected for a total of 360 leaf samples. We cut $5 \times 7 \mathrm{~mm}$ squares from the middle and along the midrib of each blade with a scalpel. The cut samples were immediately fixed in FAA ( $5 \mathrm{ml}$ of $37 \%$ formalin, $5 \mathrm{ml}$ of glacial acetic acid, and $90 \mathrm{ml}$ of $50 \%$ ethanol mixed with $5 \mathrm{ml}$ glycerin), placed in a cryopreserving box, and returned to the laboratory.

\section{Paraffin section production}

We removed the fixed samples from the FAA solution with tweezers, dehydrated them using an increasing ethanol solution gradient (50\%-100\%, every $10 \%$ for $1 \mathrm{~h}$ ), followed by an increasing xylene solution gradient (ethanol:xylene; $2: 1,1: 1,1: 2$, pure xylene, each solution for $1 \mathrm{~h}$ ), and finally immersed them in paraffin. We then made $10 \mu \mathrm{m}$ transverse sections (Lycra, Germany). The sections were dried, dewaxed, dyed (safranin $\mathrm{O}$ and fast green solution), and stuck with the paraffin microtomy (neutral gum).

\section{Leaf and midrib anatomical structural parameters}

Measured parameters included as follows: blade thickness (BT), blade upper epidermis thickness (BUET), blade lower epidermis thickness (BLET), blade upper epidermis cell length (BUECL), blade upper epidermis cell width (BUECW), blade lower epidermis cell length (BLECL), blade lower epidermis cell width (BLECW), palisade tissue thickness (PTT), spongy tissue thickness (STT), palisade tissue thickness-spongy tissue thickness ratio $(\mathrm{P} / \mathrm{S})$, palisade tissue thickness-blade thickness ratio (CTR), and spongy tissue thicknessblade thickness ratio (SR). The parameters measured in the cross-section of the midrib of the leaf include: midrib parenchyma tissue thickness (MPTT), midrib upper epidermis cell length (MUECL), midrib upper epidermis cell width (MUECW), midrib lower epidermis cell length (MLECL), midrib lower epidermis cell width (MLECW), midrib phloem thickness (MPT), and midrib xylem thickness (MXT), in which $\mathrm{P} / \mathrm{S}=\mathrm{PTT} / \mathrm{STT}, \mathrm{CTR}=\mathrm{PTT} / \mathrm{BT}, \mathrm{SR}=\mathrm{STT} / \mathrm{BT}$

\section{Image processing and data acquisition}

The data were observed and photographed under an inverted integrated microscope (Revolve, USA), in which the blade and mesophyll indexes were observed with a 10-fold mirror; and the midrib indexes were photographed with a 4-fold mirror. The exported images of leaf cross section parameters were measured by measurement software (Image Pro Plus, USA). For each parameter, the average of three random measurements (equidistance) from left to right on each image was used as the parameter value of the image, with an average of 120 measurements per altitudinal transect. The xylem and phloem are composed of multi-layer cells. The distance between the uppermost cell upper epidermis and the lowermost cell lower epidermis is taken as a measure value. The repetition of these two parameters is the same as other parameters.

\section{Data analysis}

Data were collated and analysed using SPSS 17.0 (SPSS Inc., USA). Comparison of the changed char- 
acteristics of Betula albosinensis leaf anatomical traits with altitude gradient was done with One-way ANOVA, and the significance of differences of characters among different altitudes was tested by least significant difference (LSD) multiple comparisons. Variance analysis was used to calculate the variance components of interaltitude, intra-altitude, and random errors. The phenotypic differentiation coefficients, $V_{\mathrm{st}}=\delta_{\mathrm{t} / \mathrm{s}}^{2} /\left(\delta_{\mathrm{t} / \mathrm{s}}^{2}+\delta_{\mathrm{s}}^{2}\right)$ [25], where $\delta_{\mathrm{t} / \mathrm{s}}^{2}$ is the variance between altitudes and $\delta_{\mathrm{s}}^{2}$ is the variance within altitude, were calculated for each trait to test the significance inter- and intraaltitudinal variance components. Pearson correlation analysis was used to analyze trade-offs and synergies between anatomical traits (Origin Lab, USA). Plotting was done in Origin2019b (Origin Lab, USA) and $R$ (version 4.0.3, USA).

\section{RESULTS}

\section{Anatomical traits of Betula albosinensis leaf transverse sections}

The upper and lower epidermises are made up of a single layer of closely packed irregular rectangular cells with somewhat wavy cell walls. The mesophyll divides into palisade tissue and spongy tissue with 1-2 palisade cell layers and 3-5 spongy cell layers. There are 1 to 3 vascular bundles in the midrib, the phloem in the midrib is near the leaf surface, and the xylem is in the outer layer of the phloem (Fig. 1).

\section{Effects of altitude on leaf anatomical characteristics}

One-way ANOVA showed that altitude had significant effects on BUET, BUECL, and STT $(p<0.05)$ (Table S1). The anatomical traits BT, BUET, BLET, BUECL, BUECW, and BLECL significantly decreased with increasing altitude, as did the mesophyll anatomical characters STT and SR; while CTR significantly increased. The greatest $\mathrm{P} / \mathrm{S}$ and MUECL were at 2824 m elevation (Fig. 2). Among the anatomical characteristics of the midrib, MPTT decreased significantly with increasing altitude $(p<0.05)$.

\section{Inter- and intra-altitudinal variation of leaf anatomical characters}

The coefficients of Betula albosinensis leaf phenotypic differentiation varied from $0.68 \%$ to $65.51 \%$. The mean trait variance between and within altitudes accounted for $22.86 \%$ and $73.16 \%$ of the total trait variance, respectively, indicating that phenotypic variation was mainly due to variance within an altitude. BT and MPTT had generally high variance, while CTR and SR had very low variance. Only MPTT and MUECL had higher inter-altitudinal, rather than intra-altitudinal, variance. Thus, MPTT and MUECL had high altitudinal plasticity, possibly related to ecological adaptability (Table S2).

\section{Correlation among anatomical traits}

Pearson correlation analysis of leaf anatomical traits showed that 23 out of the 171 trait combination groups were extremely and significantly correlated $(p<0.001)$, and 37 groups were significantly correlated $(p<0.05)$. Among these, BT was positively correlated with STT and PTT, as well as P/S with CTR and other traits $(p<0.001)$. SR was significantly and negatively correlated with P/S and CTR, as was MPTT with compound traits $(p<0.001)$ (Fig. 3$)$.

\section{Principal component analysis of leaf anatomical traits}

Four principal components containing $83.20 \%$ of the total variance were selected. The first principal component accounted for $44.54 \%$ of the total variance was negatively correlated with traits related to leaf photosynthetic capacity (SR and CTR) and positively correlated with traits related to leaf protection and storage (BT and MUECL) (Fig. 4A). The second principal component accounted for $22.90 \%$ of the total variance was negatively correlated with traits representing vein storage and transport capacity (MXT and MPT) and positively correlated with leaf photosynthetic capacity traits (PTT and BUECL) (Fig. 4B). The variance contribution of the third principal component was $8.50 \%$, which was significantly correlated with MPTT, representing leaf support and material transport (Fig. 4C). The variance contribution of the fourth principal component was $7.26 \%$, which was positively correlated with characteristics of vein protection (MUECW and MLECL) (Fig. 4D).

\section{DISCUSSION}

\section{Effects of altitude on leaf anatomical characteristics}

The leaves are a plant's defensive organ and a crucial barrier against harmful external environments. We found that the thicknesses of the blade, upper and lower epidermises decreased with increasing altitude, which were in contrast to earlier investigations. One possible explanation is that as altitude increases, partial pressure of $\mathrm{CO}_{2}$ decreases; and thin leaves will shorten the $\mathrm{CO}_{2}$ diffusion path leading to photosynthesis improvement [22] and be more adaptable to changes in habitat. The decrease in blade upper and lower epidermis cell length could be attributed to a loss in water control capabilities of leaf epidermal cells as UV-B levels rise with altitude. Some studies have shown that water-limited plants develop flatter epidermal cells, which reduce water loss [23] or increase the density of paraxial and lateral chloroplasts distribution, and increase light energy use rate [24]. Blade upper epidermis cell width was not significantly decreased among different altitudes. This may be associated with adaptation to the environment in gener- 

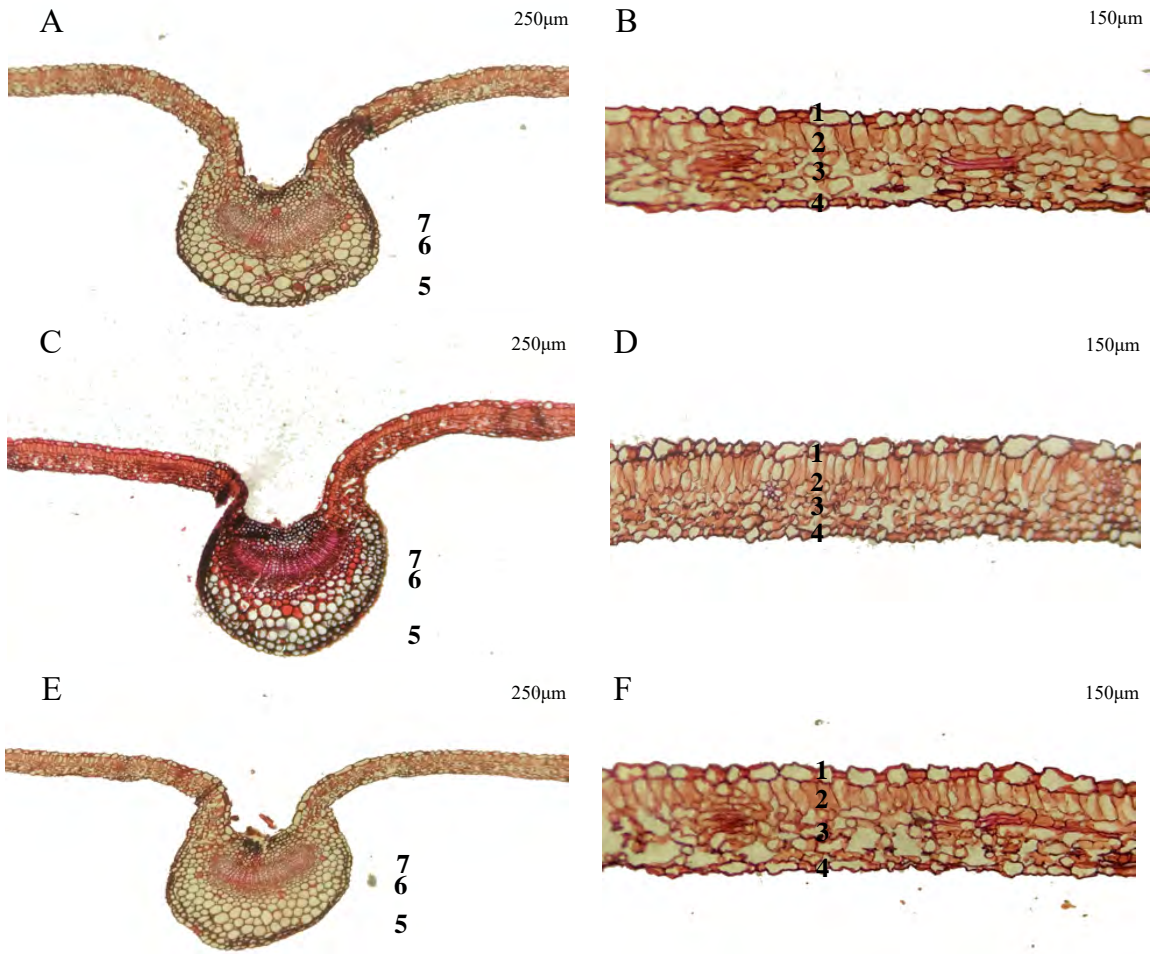

Fig. 1 Anatomical images of Betula albosinensis: A and B, at $2434 \mathrm{~m}$ elevation; C and D at $2824 \mathrm{~m}$ elevation; E and F, at $3060 \mathrm{~m}$ elevation; the image is one of all images at an altitude: 1-upper epidermis; 2-palisade tissue; 3-spongy tissue; 4-lower epidermis; midrib; 5-parenchyma; 6-phloem; 7-xylem.

ations of life, so relatively stable genetic characteristics were formed.

Photosynthesis mostly occurs in the mesophyll. Previous studies [25] have combined Kubelka-Mun theory with models of leaf photosynthesis to clarify how the differentiation of mesophyll into palisade and spongy tissues, which may be an adaptation of mesophyll to light gradients. Photosynthetic efficiency is also affected by leaf thickness and cell morphology of palisade and spongy tissues [26]. The spongy tissue, with loosely arranged cells, is closer to the epidermis and carries out gas exchange and water transpiration. In this study, the change of palisade tissue thickness among altitudes was not significant, consistent with the results of Tang Tan et al [27]. It may be that leaf palisade cells take on a protective role at higher altitudes because shortwave radiation is higher. The traits may be less plastic, and possibly under stabilizing selection, in order to prevent tissue burns caused by excessive leaf temperatures. We found that spongy tissue thickness significantly decreased with increased altitude, and that the cell walls of the smaller leaf spongy tissue were more elastic. This may help maintain turgor pressure and stomata function. At high elevations, plants must avoid mechanical damage to leaves caused by low atmospheric moisture and increased wind speed [28]. In our study, the palisade tissue thickness-spongy tissue thickness ratio increased significantly with altitude, indicating that the net photosynthetic rate of Betula albosinensis was high [29]. This may be due to high leaf oxidase activity, which allows Betula albosinensis to withstand the short growing season caused by low temperature. We further found that the palisade tissue thickness-blade thickness ratio increased significantly, while the spongy tissue thickness-blade thickness ratio decreased significantly, with altitude. Because the palisade tissue accounts for a large proportion of the leaf, the plants may be more water use efficient, as found by Xu Yang et al [30].

The midrib is the primary transport and support area of leaves, importing inorganic salts and water and exporting photosynthetic products [31]. In this experiment, midrib parenchyma cell thickness decreased with increased altitude. This underdeveloped transport tissue, conducive to water storage, heat preservation, and nutrient transmission; may compensate for low oxygen and carbon dioxide partial pressure [32] allowing plant physiological activities to proceed normally. Midrib upper epidermis cell length decreased with increasing elevation, which may relate to a decrease in cell water control ability [24]. The remaining five midrib traits did not change significantly among altitude, which indicated the plasticity associated with losses in maintenance, signal recognition, and trans- 

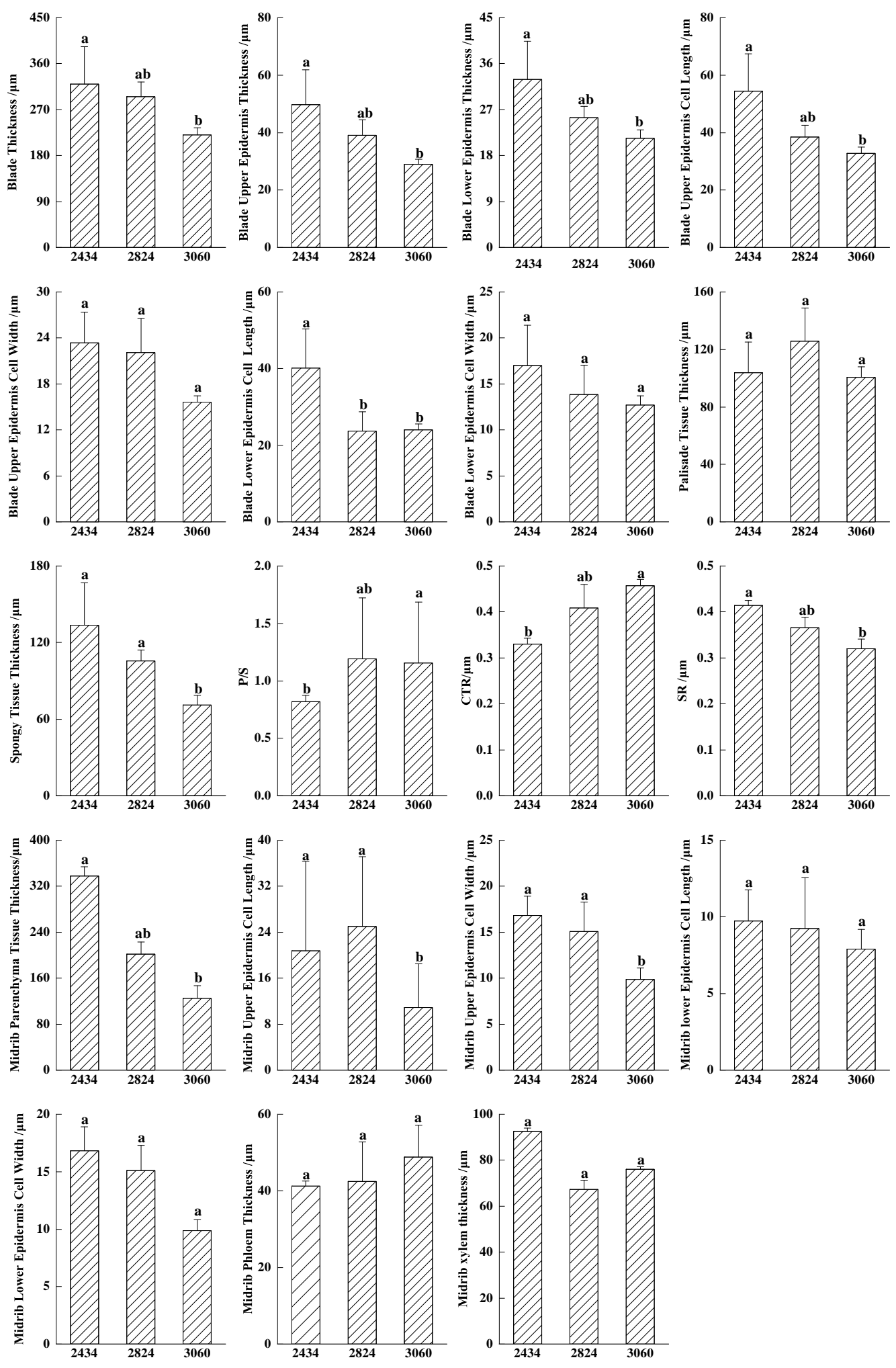

Altitude/m

Fig. 2 Distributions of leaf anatomical characteristics of Betula albosinensis at three altitudes. The solid black line on the column represents the standard deviation. Different lowercase letters indicate significant differences at 0.05 level. 


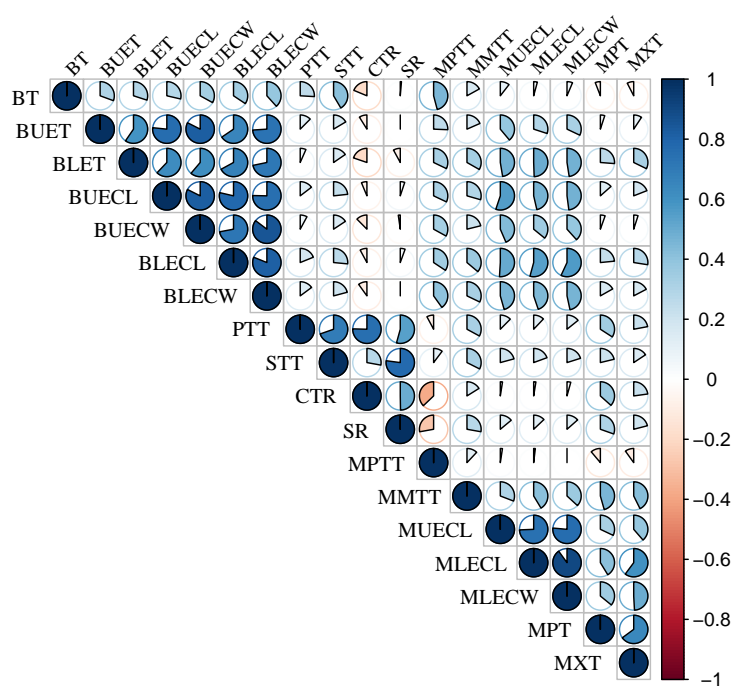

Fig. 3 Correlation matrix among anatomical characteristics of Betula albosinensis.
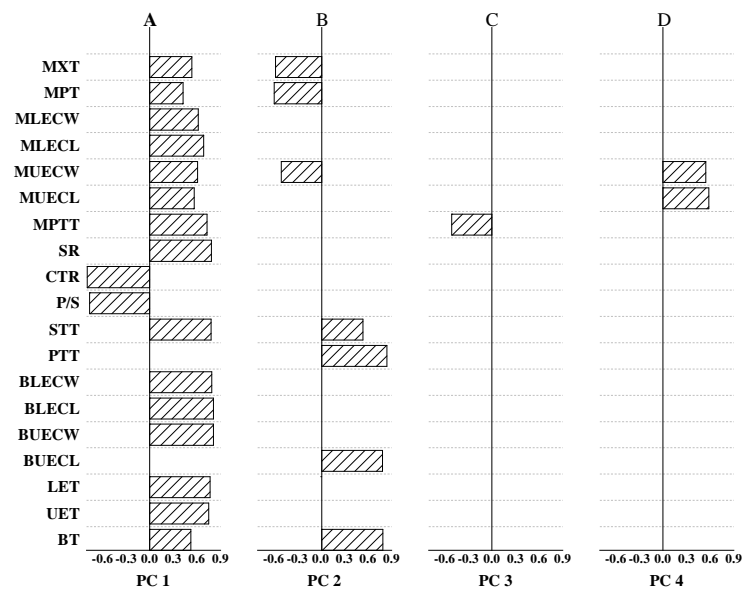

Fig. 4 Correlation between principal components (PC) and anatomical characteristics: A, PC1; B, PC2; C, PC3; D, PC4. Traits that have no significant correlation with principal components are not shown in the graph.

mission [33] making these traits insensitive to altitudinal changes.

\section{Trade-offs between leaf anatomical traits}

The phenotypic differentiation of leaf features can be strongly influenced by the environment [34]. The variability and complexity of environmental factors may be the main contributors to the conservative phenotypic variance of Betula albosinensis, which has long lived at low temperatures and high light exposure. Some traits, including blade and upper epidermis thickness, had high variance, which may implicate them as key traits for coping with adverse environments [35] enabling plants to maintain necessary physiological functions under resource constraints. The phenotypic differentiation coefficients of palisade tissue thickness, midrib phloem thickness, and midrib xylem thickness were low, which may be related to optimal resource utilization strategies [36]. The average phenotypic differentiation coefficient decreased from the leaves (26.5), to the mesophyll (20.93), to the main vein (24.1). Altitude had significant effects on midrib parenchyma tissue thickness $(p<0.05)$, and the variance between altitudes was greater than that within altitudes, indicating that these two traits may be responding to elevation, while the remaining seventeen traits may be responding to the respective microenvironments.

Under a limited resource environment, there are several trade-offs among Betula albosinensis traits. Leaf thickness, epidermal, and mesophyll characteristics had synergistic connections, which decreased the distance between stomata and leaf epidermis, possibly to enhance the rate of gas and nutrient turnover. The correlation between leaves and spongy tissue was the largest, so it can be inferred that the change of leaf thickness was mainly caused by the change of spongy tissue thickness [37]. Palisade tissue thickness and spongy tissue thickness were also synergistic; the palisade tissues are closely arranged and directly exposed to solar radiation, forming a barrier between the spongy tissues and the outside environment. Spongy tissue has loose tissue with spaces for gas exchanges, which may improve photosynthesis by accelerating the gas exchange rate. The trade-offs among blade thickness, palisade tissues thickness-spongy tissue thickness ratio, and palisade tissue thickness-blade thickness ratio indicated that the photosynthetic rate and drought tolerance of Betula albosinensis were high. There was a trade-off between blade upper epidermis cell length and midrib phloem thickness, which indicated that less investment was put into leaf construction, and more into the veins to supplement water and to resist high temperatures, sunlight, and physical damages [38]. There were no significant correlations between blade upper epidermis cell width and palisade tissue thickness, spongy tissue thickness, midrib phloem thickness, and PCA showing the first four axes corresponded to different ecological strategy dimensions.

Kitajima et al [39] believed that leaf anatomical traits could be used as leaf economic spectrum traits, and there are obvious synergies and trade-offs among leaf anatomical characteristics of Betula albosinensis possibly to resist adverse environments consistent with leaf economic spectrum. With increasing elevation, Betula albosinensis increased investment in photosynthesis and respiration and correspondingly reduced the input to leaf construction. This strategy of "quick investment-return" reflects the economic spectrum of Betula albosinensis leaves on the eastern edge of the 
Qinghai-Tibet Plateau. Whether the relationship between leaf anatomical traits at these sites can be extended to the entire region, species or the global ecosystem needs to be systematically verified. Relevant research can help further reveal adaptative strategies of plants to the environment.

Altitude affects the anatomical structure of plant leaves through multiple environmental factors. At different altitudes, Betula albosinensis adopted different strategies. First, in order to enhance plant defence capabilities, the blade, the mesophyll, and the midrib tended to be flat and closely arranged. Second, the Qinghai-Tibet Plateau only allows a 2-4 month growing season, which benefits such a "rapid investmentbenefit" strategy to amass nutrients, boost growth rates, and minimize nutrient use efficiency in a short growing season. Third, these adaptive balance and allocation strategies of material energy in plants allow them to meet the goals of survival, growth, and reproduction despite changing environmental conditions.

\section{Appendix A: Supplementary data}

Supplementary data associated with this article can be found at http://dx.doi.org/10.2306/scienceasia1513-1874. 2022.030.

Acknowledgements: This work was supported by the National Natural Science Foundation of China (31800352, 32160497), Youth Talents Supporting Program of Gansu Province (GXH20210611-11), Science and Technology Innovation Fund of Gansu Agricultural University (GSAURCZX201708), "Silk Road" grassland ecological restoration technology model research and demonstration, regular science and technology assistance to developing countries (KY 202002011). We would like to thank Elizabeth Tokarz at Yale University for her assistance with English language and grammatical editing.

\section{REFERENCES}

1. Giselle R, Cláudia F, Fábio RS (1997) Leaf anatomy plasticity of Alchornea triplinervia (Euphorbiaceae) under distinct light regimes in a Brazilian montane Atlantic rain forest. Trees 11, 469-473.

2. Chartzoulakis K, Patakas A, Kofidis G, Bosabalidis A, Nastou A (2002) Water stress affects leaf anatomy, gas exchange, water relations and growth of two avocado cultivars. Sci Hortic 95, 39-50.

3. Terashima I, Hanba YT, Danny T, Niinemets Ü (2011) Leaf functional anatomy in relation to photosynthesis. Plant Physiol 155, 108-116.

4. Barki N, Chehab H, Aissaoui F, Dabbaghi O, Attia F, Mahjoub Z (2018) Effects of mycorrhizal fungi inoculation and soil amendment with hydrogel on leaf anatomy, growth and physiology performance of olive plantlets under two contrasting water regimes. Acta Physiol Plant 40, ID 116.

5. Cornwell WK, Ackerly DD (2009) Community assembly and shifts in plant trait distributions across an environmental gradient in coastal California. Ecol Monogr 79 109-126.
6. Huarong Z, Laura W, Thomas K, Dan K (2011) Genetic variation in ecophysiological and survival responses to drought in two native grasses: Koeleria macrantha and Elymus elymoides. Great Basin Nat 71, 25-32.

7. Körner C, Bannister P, Mark AF (1986) Altitudinal variation in stomatal conductance, nitrogen content and leaf anatomy in different plant life forms in New Zealand. Oecologia 69, 577-588.

8. Ji ZJ, Qian XK, Wang CK (2013) Variations in leaf anatomy of Larix gmelinii reflect adaptation of its photosynthetic capacity to climate changes. Acta Ecol Sinica 33, 6967-6974.

9. Garnier E, Laurent G (2010) Leaf anatomy, specific mass and water content in congeneric annual and perennial grass species. New Phytol 128, 725-736.

10. Liu W, Zheng L, Qi D (2020) Variation in leaf traits at different altitudes reflects the adaptive strategy of plants to environmental changes. Ecol Evol 10, 8166-8175.

11. Dong FY (2017) Response of Leaf anatomical characteristics of Populus euphratica in different soil moisture conditions. Beijing Forestry University, China. [in Chinese]

12. Otto M, Francisco JG, Gonsalez BT (2017) Changes in $\gamma$ aminobutyric acid concentration, gas exchange, and leaf anatomy in Eucalyptus clones under drought stress and rewatering. Acta Physio Plant 39, ID 208.

13. Balasooriya B, Samson R, Mbikwa F, Vitharana U, Boeckx P, Meirvenne (2009) Biomonitoring of urban habitat quality by anatomical and chemical leaf characteristics. Environ Exp Bot 65, 386-394.

14. Yuan XT, Li FP, Gu HH (2020) Effects of high temperature on photosynthetic capacity in the leaves of creepers. ScienceAsia 46, 436-443.

15. Pérez F, Lavandero N, Ossa CG, Hinojosa LF, Arancio P, Arroyo Kalin (2020) Divergence in plant traits and increased modularity underlie repeated transitions between low and high elevations in the Andean Genus Leucheria. Front Plant Sci 11, ID 714.

16. Wang YY, Qi DH, Liu WS, Liang WB (2006) Comparison on leaf phenotypic and anatomical structures of Polygonum paleaceum along altitudinal gradients at Yulong Mountains. Acta Bot Boreali-Occident Sin 36, 70-77.

17. Shen ND, Wei MQ, Li ZR (2014) Comparative study about the anatomical structure for leave of Carumcarvi L. in different altitude. Northe Hortic 16, 31-34.

18. Zhong YM, Dong FY, Wang WJ (2017) Anatomical characteristics and adaptability plasticity of Populus euphratica in different habitats. $J$ Beijing For Univ 37, 53-61.

19. Liu MY (2018) Responses of leaf morphological and anatomical structure to elevation in an alpine plant Meconopsis integrifolia. Chin J Ecol 37, 35-42.

20. Zhang HW, Ma JY, Sun Wei (2010) Altitudinal variation in functional traits of Picea schrenkiana var. tianschanica and their relationship to soil factors in Tianshan Mountains, Chin J Ecol 30, 5747-5758.

21. Cheng GP, Yang KT, Wang L, Wang F, Cao XW, Chen LS (2020) Allometric relations for biomass partitioning of seven alpine Rhododendron species in south of Gansu. Chin J Plant Ecol 44, 1040-1049.

22. Yann V, Armando L, Chris K, Christophe FR (2014) Genetic vs. nonâĂ Ǩgenetic responses of leaf morphology and growth to elevation in temperate tree species. Funct Ecol 28, 243-252.

23. Kajornjita P, Saensoukb S, Saensouka P (2018) Pollen 
morphology and leaf anatomy of genus Globba in Thailand. ScienceAsia 44, 146-161.

24. Bassman JH, Edwards GE, Ronald R (2003) Photosynthesis and growth in seedlings of five forest tree species with contrasting leaf anatomy subjected to supplemental UV-B radiation. For Sci 2, 176-187.

25. Miyazawa S, Terashima I (2010) Slow development of leaf photosynthesis in an evergreen broad-leaved tree, Castanopsis sieboldii: relationships between leaf anatomical characteristics and photosynthetic rate. Plant Cell Environ 24, 279-291.

26. Nawarathna RN, Dassanayake KB, Nissanka SP, Seneweera S, Salisbury P (2017) Is phenotypic variability in leaf vein density in rice associated with grain yield?. $J$ Rice Res Dev 1, 1-9.

27. Tang T, Jiang YL, Wang JH (2015) An eco-anatomical study on Abies georgei var. smithii leaves at gradient elevation in Northwest of Yunnan. Acta Agric Universities 37, 218-224.

28. Li FL, Bao WK, Liu JH, Wu Y (2006) Eco-anatomical characteristics of Sophora davidii leaves along an elevation gradient in upper Minjiang River dry valley. $J$ Appl Ecol 17, 5-10.

29. Hirokazu H, Tetsuo S, Naoki U (1999) Photosynthesis, leaf morphology, and shoot growth as affected by temperatures in cherimoya (Annona cherimolia Mill.) trees. Sci Hortic 80, 91-104.

30. Xu Y (2016) Anatomical characteristics of vegetative organs of four species of Malus plants in western Sichuan Plateau and their drought resistance strategy evaluation. Sichuan Agricultural University, China. [in Chinese]

31. Robledano F, Romero D, Belmonte F, Zapata V, Martinez L (2014) Eco-geomorphological consequences of land abandonment in semiarid Mediterranean areas: Inte- grated assessment of physical evolution and biodiversity. Agric Ecosyst Environ 197, 222-242.

32. Zhou GT, Liu FQ, Guo SX, Wu XM (1992) A study of characteristics of the anatomical structure of alpine plants at Qinghai plateau. J Qinghai Norm Univ Nat Sci Ed 4, 45-46.

33. Cheng MS, Ke SS (2013) Acclimation of anatomical structure and photosynthesis characteristics in leaves of Carpinus tientaiensis to irradiance. For Sci 49, 46-53.

34. Wang M, Liu GH, Jin TT, Shan Z, Gong L (2017) Erratum to: age-related changes of leaf traits and stoichiometry in an alpine shrub (Rhododendron agglutinatum) along altitudinal gradient. $J$ Mt Sci 14, 106-118.

35. Maire V, Gross N, Hill D (2013) Disentangling coordination among functional traits using an individual-centred model: impact on plant performance at intra- and interspecific Levels. PLoS One 8, e77372.

36. Li L, Liu T, Liu B, Liu ZQ, Si LM, Zhang R (2010) Phenotypic variation and covariation among natural populations of Arabidopsis thaliana in North Xinjiang. Biodiversity Sci 18, 497-508.

37. Blonder B, Violle C, Enquist BJ (2013) Assessing the causes and scales of the leaf economics spectrum using venation networks in Populus tremuloides. $J$ Ecol 101, 981-989.

38. Coble AP, Cavaleri MA (2017) Vertical leaf mass per area gradient of mature sugar maple reflects both heightdriven increases in vascular tissue and light-driven increases in palisade layer thickness. Tree Physiol 37, 1337-1351.

39. Kitajima K, Poorter L (2010) Tissue-level leaf toughness, but not lamina thickness, predicts sapling leaf life span and shade tolerance of tropical tree species. New Phytol 186, 708-721. 


\section{Appendix A. Supplementary data}

Table S1 One-way ANOVA of Betula albosinensis leaf anatomical traits with elevation.

\begin{tabular}{lcccc}
\hline Leaf traits & Quadratic sum & Mean square & F & P \\
\hline BT & 32401.01 & 16200.50 & 3.38 & 0.06 \\
UET & 1069.70 & 534.85 & 4.01 & 0.04 \\
LET & 307.08 & 153.54 & 3.39 & 0.06 \\
BUECL & 1054.48 & 527.24 & 4.27 & 0.03 \\
BUECW & 218.36 & 109.18 & 2.21 & 0.14 \\
BLECL & 663.70 & 331.85 & 3.21 & 0.06 \\
BLECW & 41.765 & 20.88 & 0.64 & 0.54 \\
PTT & 2361.98 & 1180.99 & 0.77 & 0.48 \\
STT & 10264.74 & 5132.37 & 5.96 & 0.01 \\
P/S & 1.35 & 0.67 & 2.74 & 0.09 \\
CTR & 0.04 & 0.01 & 2.95 & 0.08 \\
SR & 0.02 & 0.01 & 3.28 & 0.06 \\
MPTT & 104258.78 & 52129.37 & 8.02 & $<0.01$ \\
MUECL & 762.63 & 381.31 & 12.62 & $<0.0001$ \\
MUECW & 130.28 & 65.14 & 1.68 & 0.21 \\
MLECL & 158.09 & 79.04 & 2.48 & 0.12 \\
MLECW & 10.76 & 5.38 & 0.34 & 0.72 \\
MPT & 207.54 & 103.77 & 0.19 & 0.83 \\
MXT & 1274.18 & 637.09 & 0.40 & 0.67 \\
\hline
\end{tabular}

Table S2 Partitioning of phenotypic variance of Betula albosinensis leaf anatomical characteristics.

\begin{tabular}{|c|c|c|c|c|c|c|c|}
\hline \multirow{2}{*}{$\begin{array}{l}\text { Leaf anatomical } \\
\text { traits }(\mu \mathrm{m})\end{array}$} & \multicolumn{3}{|c|}{ Variance component } & \multicolumn{3}{|c|}{ Percentage of total variance component } & \multirow{2}{*}{$\begin{array}{c}\text { Phenotype } \\
\text { differentiation } \\
\text { coefficient (\%) }\end{array}$} \\
\hline & $\begin{array}{c}\text { Among } \\
\text { altitudes }\end{array}$ & $\begin{array}{l}\text { Within } \\
\text { altitude }\end{array}$ & $\begin{array}{c}\text { Random } \\
\text { errors }\end{array}$ & $\begin{array}{c}\text { Among } \\
\text { altitudes }\end{array}$ & $\begin{array}{l}\text { Within } \\
\text { altitude }\end{array}$ & $\begin{array}{c}\text { Random } \\
\text { errors }\end{array}$ & \\
\hline BT & 32401.01 & 71987.21 & 5438.66 & 29.50 & 65.55 & 4.95 & 31.04 \\
\hline BUET & 1069.70 & 2002.35 & 19.02 & 34.61 & 64.78 & 0.62 & 34.82 \\
\hline BLET & 307.08 & 677.49 & 0.31 & 31.18 & 68.79 & 0.03 & 31.19 \\
\hline BUECL & 1031.07 & 1853.03 & 23.41 & 35.46 & 63.73 & 0.81 & 35.75 \\
\hline BUECW & 168.26 & 741.65 & 50.11 & 17.53 & 77.25 & 5.22 & 18.49 \\
\hline BLECL & 663.70 & 1853.03 & 156.24 & 24.83 & 69.32 & 5.85 & 26.37 \\
\hline BLECW & 41.77 & 490.27 & 0.95 & 7.84 & 91.98 & 0.18 & 7.85 \\
\hline PTT & 157.46 & 22875.42 & 2204.52 & 0.62 & 90.64 & 8.74 & 0.68 \\
\hline STT & 9796.90 & 12895.97 & 467.84 & 42.30 & 55.68 & 2.02 & 43.17 \\
\hline $\mathrm{P} / \mathrm{S}$ & 1.32 & 3.69 & 0.03 & 26.21 & 73.19 & 0.60 & 26.37 \\
\hline CTR & 0.04 & 0.94 & 0 & 3.79 & 96.21 & 0.00 & 3.79 \\
\hline SR & 0.02 & 0.05 & 0 & 30.56 & 69.44 & 0.00 & 30.56 \\
\hline MPTT & 104258.76 & 97433.39 & 50.65 & 51.68 & 48.29 & 0.25 & 51.74 \\
\hline MUECL & 762.62 & 453.12 & 420.69 & 46.60 & 27.69 & 25.71 & 62.73 \\
\hline MUECW & 130.28 & 581.53 & 98.67 & 16.07 & 71.75 & 12.17 & 18.30 \\
\hline MLECL & 158.09 & 477.16 & 26.26 & 23.90 & 72.13 & 3.97 & 24.81 \\
\hline MLECW & 10.76 & 237.93 & 1.60 & 4.30 & 95.06 & 0.64 & 4.33 \\
\hline MPT & 207.54 & 8226.49 & 46.23 & 2.45 & 97.01 & 0.55 & 2.46 \\
\hline MXT & 1274.18 & 23624.05 & 872.97 & 4.94 & 91.67 & 3.39 & 5.12 \\
\hline Mean & 8023.19 & 12969.20 & 519.90 & 22.86 & 73.16 & 3.98 & 24.18 \\
\hline
\end{tabular}

